\title{
Solar reflectance performance of roof coverings in Istanbul, Turkey
}

\author{
Sinem Kultur ${ }^{1, *}$, Nil Turkeri ${ }^{2}$ \\ ${ }^{1}$ Bahcesehir University, Istanbul, Turkey \\ ${ }^{2}$ Istanbul Technical University, Istanbul, Turkey \\ *Corresponding author.Tel: +90 2123810515, Fax:+90 2123810500,E-mail: sinemkultur@gmail.com
}

\begin{abstract}
Cooling energy load can be reduced by reflective roofs. The reflective roofs are recognized by Turkish architects, contractors and manufacturers, however, the solar reflectance performance of new and aged roof coverings produced in Turkey is still unknown. Purpose of this paper is to assess short-term and long-term solar reflectance performance of these roof coverings. In this context, solar reflectance measurements were conducted both in laboratory and in field. Firstly, solar reflectance performance of 13 unexposed test samples including clay, cement, bituminous and metal based was measured in laboratory. Then, 6 of these test samples were exposed to simulated solar radiation for a duration that is equivalent to 1-year exposure. The laboratory measurements indicated that white and shiny ceramic tile is the most reflective covering while black corrugated sheet is the most absorptive one. Secondly, two test specimens (red clay tile and bituminous shingle covered surfaces) with an automated weather observation system were set up in a field in order to measure the solar reflectance performance of the roof surfaces. The initial results demonstrated that the clay tile-covered roof surface had higher reflectance values. This paper will enable designers to choose the roof covering appropriate for reflective roofs that can be used to rehabilitate existing roof coverings or to design new roofs.
\end{abstract}

Keywords: Solar reflectance performance, Roof covering, Reflective roof.

\section{Introduction}

Future climate projections demonstrate that the western part of Turkey will experience temperature increases up to $6^{\circ} \mathrm{C}$ notably in summer in addition to urban heat island effect, whereas the temperature increase for the entire country is estimated to be around $2-3^{\circ} \mathrm{C}$ (The Ministry of Environment and Foresty, 2007). Increase in temperature will result in increase in summer cooling load, electricity consumption and amount of carbon dioxide in atmosphere. Survey of literature indicates that cooling energy load can be reduced by reflective roofs which comprise high-albedo roof coverings that have high solar reflectance and high infrared emittance and maintain these properties for the service life of the covering (Liu, 2005).

There are many researches that assess short-term and long-term solar reflectance performance of materials both in laboratory and in field. In one of these researches, a series of field measurements was conducted on 9 residential buildings in Florida, USA (Parker et.al., 1995) in order to determine the impact of reflective roof coatings on buildings' air-conditioning energy use. Results of the research indicated that application of white coloured reflective coatings can reduce cooling energy consumption in between $2 \%$ and $43 \%$. In the same study, reflective coatings under actual conditions experience a reduction in their solar reflectance rates from $71 \%$ to $47 \%$ in value at the end of 1 -year.

Another research (Prado and Ferreira, 2005) conducted in laboratory presents the long-term solar reflectance performance results of roofing materials commonly used in Brazil. In this study, long-term solar reflectance rates were calculated from a mathematical equation defined by California Energy Commission. The roofing materials' surface temperatures were calculated according to their emittance and reflectance rates. The results demonstrated that same coloured metallic and ceramic materials reached different surface temperatures according to their emittances. 
Benefits of reflective roofs are recognized by Turkish architects, contractors, and manufacturers, however, the solar reflectance performance of new and aged roof coverings produced in Turkey is still unknown. Therefore, short-term and long-term solar reflectance performance of roof coverings that are produced and commonly used in Turkey were measured in laboratory and in field. Purpose of this paper is to describe methodology and to present results of the measurements.

\section{Methodology}

Solar reflectance measurements of the roof coverings were conducted both in laboratory and in field.

\subsection{Laboratory measurement}

\subsubsection{Test specimens}

Types of roof coverings were determined according to the research conducted by Çatıder (Association of roofing industrialists and businessmen in Turkey) which presented the market share distribution of roof coverings in Turkey for the year of 2007 (Ozturk, 2008). Clay, cement, metal and bitumen based 13 roof coverings were determined. 2 of them are commonly used in flat roofs while the remaining are the coverings having highest market shares defined at the list of the research. The selected roof coverings with their materials and colour/surface characteristics are given in Table 1.

Table 1. Test specimens.

\begin{tabular}{|c|c|c|c|}
\hline \multicolumn{2}{|c|}{ Roof Coverings/Test specimens } & Colour / Surface & Roof Slope \\
\hline \multirow{3}{*}{ Clay based } & Tile & Red & Steep \\
\hline & Ceramic tile & White & Low slope \\
\hline & Ceramic tile & White-shiny & Low slope \\
\hline $\begin{array}{c}\text { Cement } \\
\text { based }\end{array}$ & Concrete Tile & Red & Steep \\
\hline \multirow{6}{*}{ Metal based } & Tile & Red/natural granule covered & Steep \\
\hline & Galvanised sheet & White & Low slope \\
\hline & Aluminium sheet & Silver & Low slope \\
\hline & Copper sheet & Bronze & Low slope \\
\hline & Titanium-zinc sheet & Black & Low slope \\
\hline & Titanium-zinc sheet & Silver & Low slope \\
\hline \multirow{3}{*}{$\begin{array}{c}\text { Bitumen } \\
\text { based }\end{array}$} & Membrane & Red/natural granule covered & Low slope \\
\hline & Shingle & Red & Steep \\
\hline & Sheet & Black/corrugated & Low slope \\
\hline
\end{tabular}

Red colour was held constant for a later comparison between some test specimens depending on the material composition and surface roughness since most of the roof coverings can be produced in red colour. Dimensions of the specimens range from $4 \times 4-\mathrm{cm}$ to $10 \mathrm{x} 10-\mathrm{cm}$ as 
described in ASTM E 903-96 "Standard Test Method for Solar Absorptance, Reflectance and Transmittance of Materials Using Integrated Spheres”.

\subsubsection{Test instruments}

Spectrophotometer; a radiation measuring device in a sensitivity range between $200 \mathrm{~nm}$ and $2500 \mathrm{~nm}$ was used for the solar reflectance measurements. It has a 150-mm diameterintegrating sphere attached at its center where the test specimens were placed. At the beginning of the measurements, the spectrophotometer was calibrated with a mirror (as a reference sample) for calculating the reflectances of other materials (ASTM E 903-96, 1996). Accelerated weathering tester; a device was used for exposure of the specimens to xenon arch light (simulated solar radiation). It can run out at the spectral range of 300 to $800 \mathrm{~nm}$. The environmental stresses on roofing; exposure to wind, moisture, atmospheric gases, pollutants and biological growth were not within the scope of this simulation.

\subsubsection{Test protocol}

The test method described in ASTM E 903-96 "Standard Test Method for Solar Absorptance, Reflectance and Transmittance of Materials Using Integrated Spheres” was followed for measuring reflection rates of new and aged roof coverings in laboratory.

Initially, the spectrophotometer was calibrated at $1 \mathrm{~nm}$ intervals and then a 12-minute measurement was performed for each test specimen. UV-WIN software was used to obtain test results and graphics. The test results and the graphic demonstrations were converted to Excel format, then, calculated and assessed as average reflectance rates at each spectral range (ultraviolet, visible and infrared). After that, 6 of these test samples excluding metallic ones were determined to be exposed to xenon arc light in accordance with the standard ASTM G155-05a "Standard Practice for Operating Xenon Arc Light Apparatus for Exposure of NonMetallic Materials". The selected specimens were put into the accelerated weathering tester for 50 day-period which corresponds to 1-year exposure. One sample of each material was left as unexposed for making comparison between new and aged situations. Finally, a series of measurement was conducted using the spectrophotometer for aged test specimens.

\subsection{Field measurement}

Field measurements were performed at the campus of Istanbul Technical University in Ayazağa, Istanbul. For conducting the measurements, approximately $100-\mathrm{m}^{2}$ area was organized.

\subsubsection{Test specimens}

2 types of test specimens were specified as clay based tile and bitumen based shingle. Both of the roof coverings were in red colour and were applied in order to set up $4.00 \times 4.00-\mathrm{m}$ dimensioned two roof surfaces. The roof surfaces were sloped to provide drainage of rain water.

\subsubsection{Test instruments}

Automated weather observation system (AWOS) were set up for field measurements. It comprises a pyranometer, a data logger, a solar panel, a temperature sensor, wind direction sensor, a moisture sensor, a rain sensor and a sensor measuring earth's temperature. In addition to AWOS, a pyranometer and a portable data logger were placed in order to measure reflected solar radiation. Thus, incoming solar radiation data was obtained from the data 
logger of the AWOS while reflected solar radiation data was obtained from the portable data logger.

Pyranometer; a radiation measuring device in a sensitivity range between $305 \mathrm{~nm}$ and 2800 nm was used for the solar reflectance measurements. 2 pyranometers were located back to back to build up an albedometer.

Data logger: Pyranometer's analog data was converted to and collected as digital data by the data logger.

\subsubsection{Test setup and protocol}

Test specimens were located facing the south direction. The automated weather observation system was erected on wheels to be driven over the two test specimens. Test setup is shown in Fig. 1. The measurements were conducted under the actual environmental conditions according to test method given in ASTM 1918-06 Standard Test Method for Measuring Solar Reflectance of Horizontal and Low Sloped Surfaces in the Field. The data obtained from the measurements in ASCII format was transferred to a PC computer and converted to Excel format. Then the averages of initial solar reflectances were calculated.

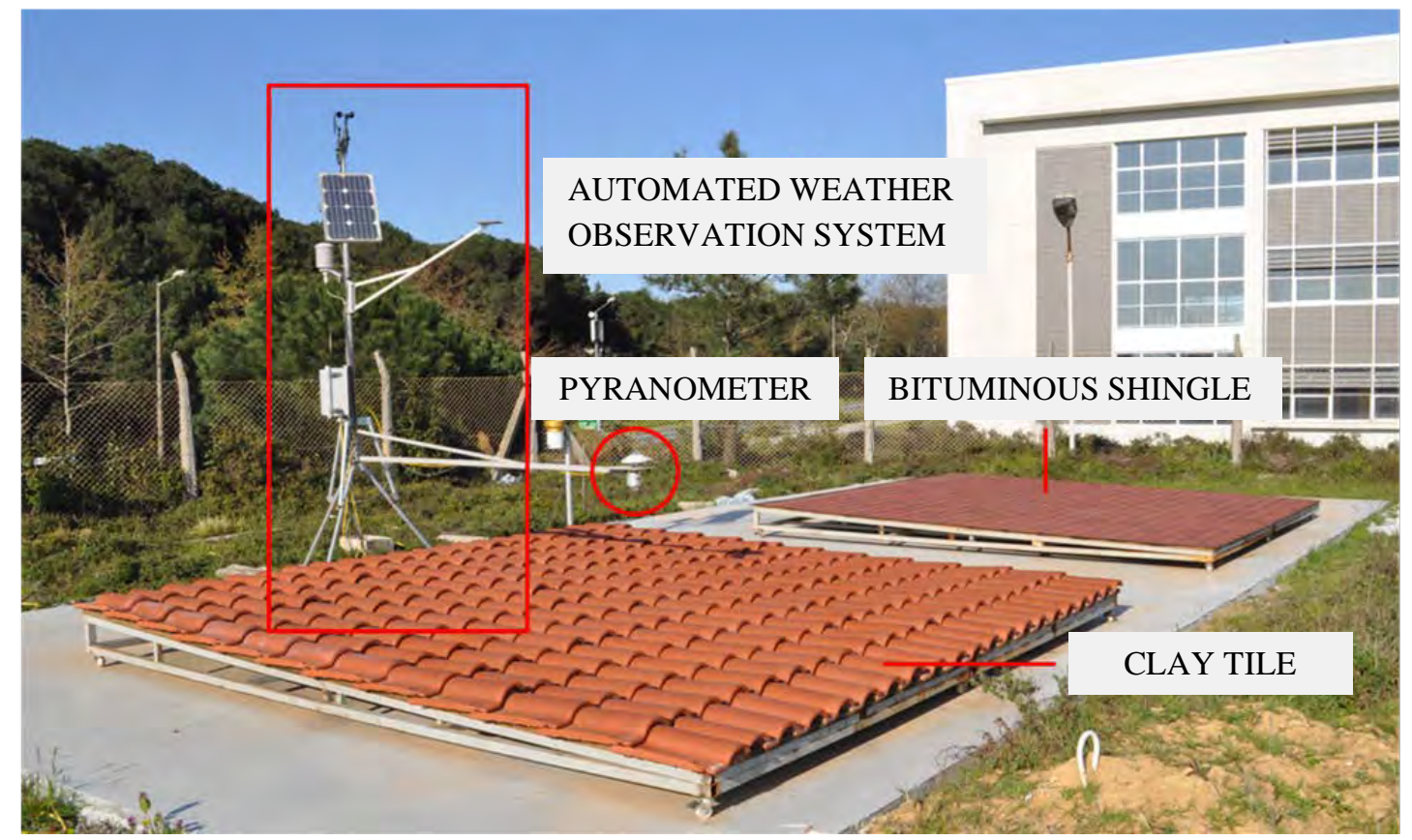

Fig. 1. Test setup.

\section{Results}

\subsection{Laboratory measurement}

The test results of new and 1-year aged test specimens are given in Table 2. Solar reflectance rates of each roofing material for each spectral range and situation (new-aged) are presented. Spectral ranges are stated in four sections as ultraviolet (UV), visible (VIS), infrared (IR) and total. 
Table 2. Solar reflectance rates of new and 1-year aged roofing materials.

SOLAR REFLECTANCE RATES \% R

ROOFING

MATERIALS /

TEST SPECIMENS

AGED (1-YEAR EXPOSED)

NEW (UNEXPOSED)

SPECTRUM (NM)
SPECTRUM (NM)

\begin{tabular}{cccccccc}
\hline UV & VIS & IR & TOTAL & UV & VIS & IR & TOTAL \\
\hline $200-$ & $380-$ & $780-$ & $200-$ & $200-$ & $380-$ & $780-$ & $200-$ \\
380 & 780 & 2500 & 2500 & 380 & 780 & 2500 & 2500 \\
\hline
\end{tabular}

CLAY BASED

\begin{tabular}{lcccccccc}
\hline TILE-RED & 6.05 & 21.28 & 73.46 & $\mathbf{3 5 . 4 0}$ & 7.10 & 22.42 & 73.60 & $\mathbf{3 5 . 9 0}$ \\
\hline $\begin{array}{l}\text { CERAMIC TILE- } \\
\text { WHITE }\end{array}$ & 15.09 & 71.73 & 75.80 & $\mathbf{7 0 . 4 0}$ & --- & --- & --- & --- \\
\hline $\begin{array}{l}\text { CERAMIC TILE- } \\
\text { WHITE,SHINY }\end{array}$ & 27.98 & 83.00 & 76.96 & $\mathbf{7 7 . 8 0}$ & 29.39 & 82.16 & 76.70 & $\mathbf{7 8 . 1 0}$ \\
\hline
\end{tabular}

CEMENT BASED

$\begin{array}{lllllllll}\text { CONCRETE TILE-RED } & 6.98 & 24.71 & 43.20 & \mathbf{2 9 . 7 0} & 7.16 & 25.10 & 43.59 & \mathbf{2 9 . 7 0}\end{array}$

\section{METAL BASED}

\begin{tabular}{lcccccccc}
\hline $\begin{array}{l}\text { TILE-RED, N. } \\
\text { GRANULE COVERED }\end{array}$ & 3.62 & 10.13 & 36.64 & $\mathbf{1 7 . 2 0}$ & --- & --- & --- & --- \\
\hline $\begin{array}{l}\text { GALVANISED SHEET- } \\
\text { WHITE }\end{array}$ & 7.16 & 77.72 & 64.61 & $\mathbf{7 0 . 7 0}$ & --- & -- & -- & --- \\
\hline $\begin{array}{l}\text { ALUMINIUM-SILVER } \\
41.56\end{array}$ & 61.32 & 75.88 & $\mathbf{6 4 . 0 0}$ & --- & --- & --- & --- \\
\hline COPPER-BRONZE & 7.25 & 22.97 & 63.32 & $\mathbf{3 3 . 2 0}$ & --- & --- & --- & --- \\
\hline $\begin{array}{l}\text { TITANIUM ZINC- } \\
\text { BLACK }\end{array}$ & 6.75 & 6.03 & 9.58 & $\mathbf{6 . 2 0}$ & --- & --- & -- & --- \\
\hline $\begin{array}{l}\text { TITANIUM ZINC- } \\
\text { SILVER }\end{array}$ & 43.30 & 55.10 & 72.61 & $\mathbf{5 4 . 7 0}$ & --- & --- & --- & --- \\
\hline BITUMINOUS BASED & & & & & & & & \\
\hline $\begin{array}{l}\text { ROLL-RED, N. } \\
\text { GRANULE COVERED }\end{array}$ & 5.36 & 12.84 & 21.75 & $\mathbf{1 4 . 8 0}$ & 5.59 & 13.38 & 22.00 & $\mathbf{1 5 . 2 0}$ \\
\hline $\begin{array}{l}\text { SHINGLE-RED } \\
\text { CORRUGATED }\end{array}$ & 4.66 & 9.32 & 10.09 & $\mathbf{9 . 3 0}$ & 3.64 & 9.78 & 10.68 & $\mathbf{9 . 7 0}$ \\
\hline \begin{tabular}{l} 
SHEET-BLACK \\
\hline
\end{tabular}
\end{tabular}

\subsection{Field measurement}

Initial results of field measurements are demonstrated graphically for each roof surface in Fig 2. and Fig. 3. 


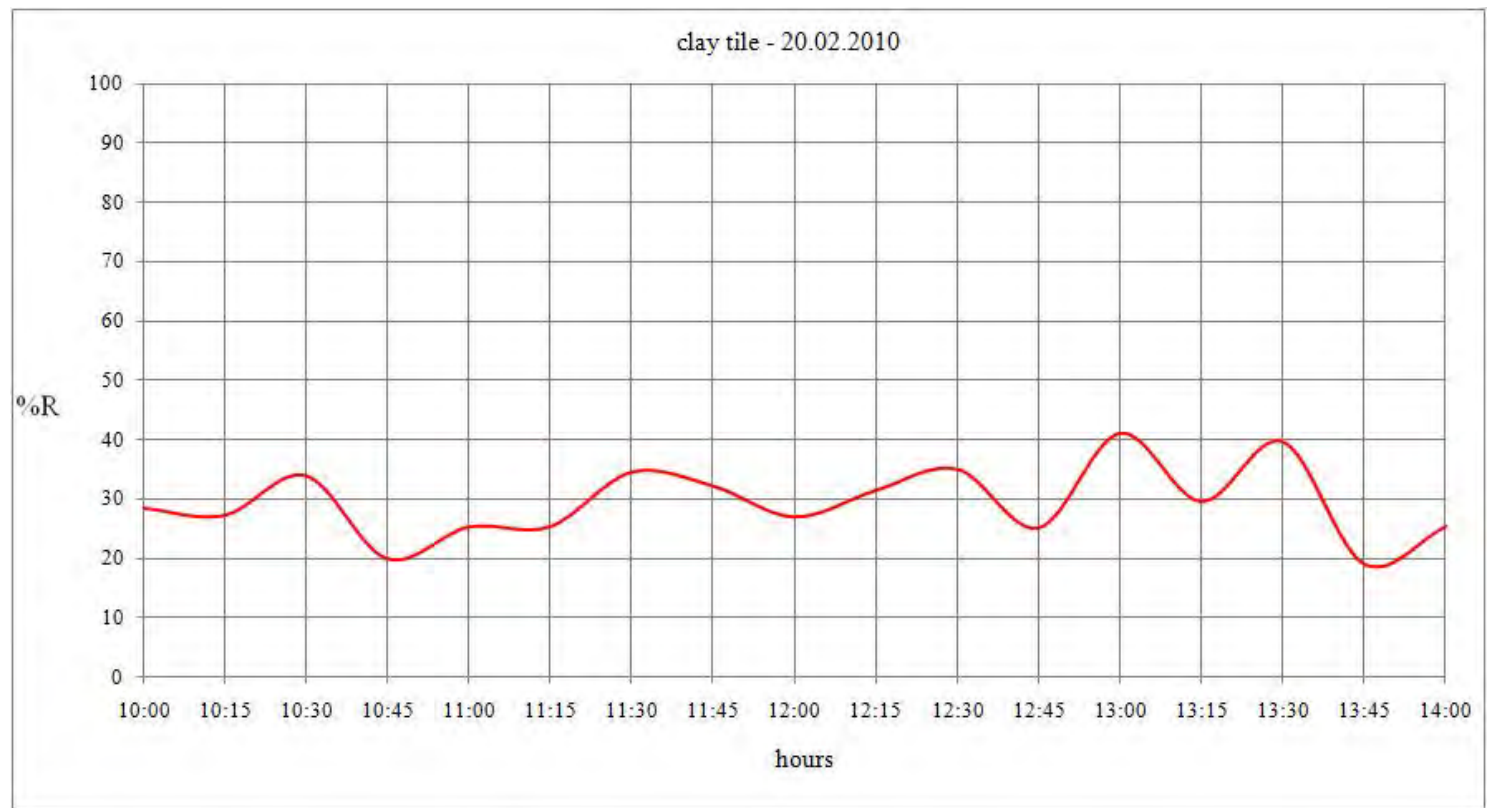

Fig. 2. The initial measurement results of clay tile covered roof surface for 20 February 2010.

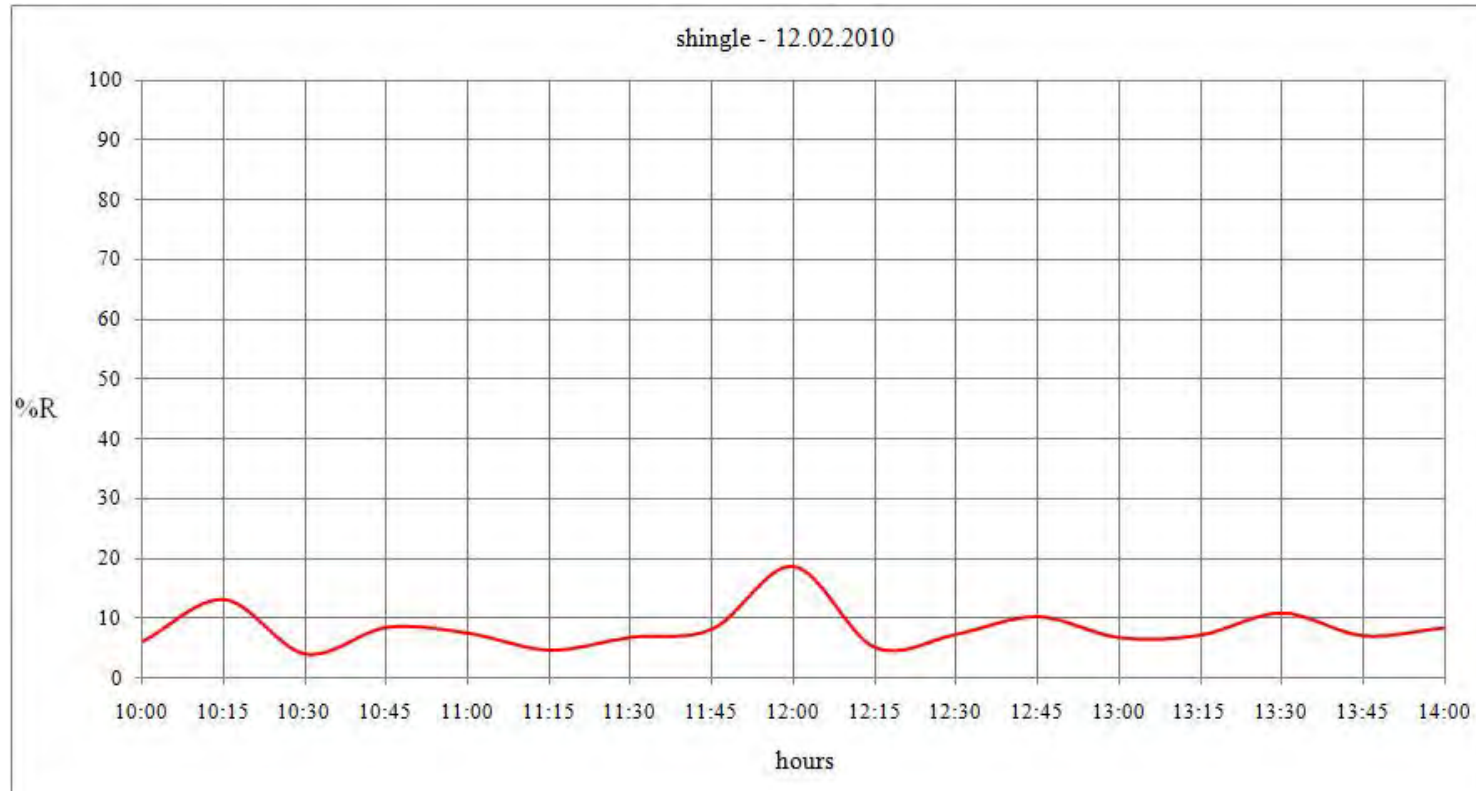

Fig. 3. The initial measurement results of bituminous shingle covered roof surface for 12 February.

The measurement results enable comparative assessment between the same colored and same sloped (3\%) roof surfaces under actual weather conditions. The average solar reflectance performance of roof surfaces was calculated from the initial measurement results of the days without rain. Accordingly, the initial solar reflectance performance of clay tile covered roof surface is $29 \%$, while bituminous shingle covered roof surface has an initial value of $\% 8$.

\section{Discussion and Conclusions}

This paper presents the solar reflectance performance of roof coverings used in Istanbul, Turkey. In accordance with this purpose, the laboratory and the field measurements were conducted. 
The laboratory measurements' results can be assessed in two ways as short-term and longterm solar reflectance performance of roof coverings. For the short-term performance, the most reflective roofing material is the white and shiny clay based ceramic tiles while the black corrugated bituminous based sheet has the lowest solar reflectivity. On the other hand, only in the ultraviolet spectrum, the silver coloured titanium-zinc is the most reflective material. Reflectivity in the UV region indicates the sensitivity to UV radiation, hence material degradation. After accelerated 1-year exposure, all the materials had almost the same performance with their short-term performance and no change in appearance was observed (Table 2).

The field measurements' initial results enable the comparisons between 2 roof surfaces under the same conditions. The red coloured clay tile covered roof surface is more reflective than the same coloured shingle covering. The laboratory and the field measurements have approximately the same results when initial solar reflectance rates of red clay tile and red bitumen shingle are considered.

Environmental Protection Agency (EPA) had described the reflective roofing materials according to their application on low-sloped or steep roofs. Based on EPA, for instance, the red clay tile can be considered as reflective roof covering while red bitumen shingle as absorptive material.

Field measurements will be conducted for 1-year in order to evaluate effect of weathering on the solar reflectance performance. Then, the long-term solar reflectance performance results of laboratory and field measurements will be compared.

Results of this paper will enable designers to choose the roof covering appropriate for reflective roofs that can be used to rehabilitate existing roof coverings or to design new roofs, which in return will provide cooling energy savings and hence sustainable development of Turkey.

\section{References}

[1] American Society for Testing and Materials. (1996). Standard Test Method for Solar Absorptance, Reflectance and Transmittance of Materials Using Integrated Spheres. ASTM Standards, E 903. USA: ASTM International.

[2] American Society for Testing and Materials. (2001). Standard Practice for Operating Xenon Arc Light Apparatus for Exposure of Non-Metallic Materials, ASTM Standards, G 155, USA: ASTM International.

[3] American Society for Testing and Materials. (2006). Standard Test Method for Measuring Solar Reflectance of Horizontal and Low Sloped Surfaces in the Field. ASTM Standards, E 1918. USA: ASTM International.

[4] Liu, K. (2005). Towards Sustainable Roofing. Institute for Research in Construction. Canada, <http://irc.nrccnrc.gc.ca/pubs/fulltext/nrcc48173/nrcc48173.pdf>, accessed on 20.04.2009.

[5] Ozturk, M. (2008). Eğimli Çatılarda Nihai Çatı Kaplama Malzemeleri 2007 Yılı Sektör Büyüklüğü Araştırması. 4. Ulusal Çatı \& Cephe Kaplamalarında Çağdaş Malzeme ve Teknolojiler Sempozyumu (s. 115-120). İstanbul: Altan Basım Ltd.. 
[6] Parker, D.S., Barkaszi, S., Chandra, S. and Beal, D.J. (1995). Measured cooling energy savings from reflective roofing systems in Florida: field and laboratory research results. Report No: FSEC-PF-293-95 Florida Solar Energy Center, FL.

[7] Prado, R. and Ferreira, F. (2005). Measurement of albedo and analysis of its influence the surface temperature of building roof materials. Energy and Buildings, 37, 295-300.

[8] The Ministry of Environment and Foresty. (2007). First National Communication on Climate Change. <http://www.cevreorman.gov.tr>, accessed on 15.03.2007. 